\title{
Potentials of Internet of Things (IoT) in Malaysian Construction Industry
}

\author{
Syamsul H. Mahmud ${ }^{1,}{ }^{*}$, Laromi Assan ${ }^{1}$, Rashidul Islam ${ }^{1}$ \\ ${ }^{1}$ Faculty of Built Environment, Universiti Teknologi Malaysia, Skudai, 81310 Johor, Malaysia \\ b-syamsul@utm.my, laromiofficial@gmail.com, mrislam1080@gmail.com \\ *Correspondence: $\underline{\text { b-syamsul@utm.my }}$
}

Received: $2^{\text {nd }}$ August 2018; Accepted: 25 $5^{\text {th }}$ August 2018; Published: $1^{\text {st }}$ October 2018

\begin{abstract}
IoT is a man-made technology conceptualized by intelligent virtual objects, which capable of knowing all things and allows the devices around themselves to interact automatically without human control. Every year, the number of IoT devices usage is exponentially increasing and estimated as much as 75.44 billion devices will be connected in IoT network. In line with the expansion of the IoT network, the construction industry should take into consideration as otherwise the construction industry will be left behind by other industries. This is because the construction industry should utilize the applications offered by IoT to ensure the smoothness of the construction industry in the project. Therefore, the objective of this study is to identify the types of IoT applications used in the construction industry in Malaysia. The research method used to identify the types of IoT applications used is through the questionnaire method. The questionnaire was analysed using nominal analysis. A study was conducted on construction industry players which comprising of government agencies, developers, architects, engineers, quantity surveyors and class G7 contractors covering all states in Malaysia. The findings show that among the many types of IoT applications used by construction industry players are social media such as WhatsApp, Telegram and Facebook for discussion and communication purposes, the use of email for information and communication exchange and website usage as a source of reference to obtain data on company profiles, acts and policy, price quotes and so on.
\end{abstract}

Keyword: Internet of Things; Construction Industry; Industrial Revolution 4.0; Augmented Reality; Waste Management

\section{Introduction}

The construction industry is one of the major contributors to the national economy as the construction sector is increasing every year in Malaysia. Construction Industry Development Board (CIDB) of Malaysia expects that growth of construction sector is eight (8) percent in 2018. This is expected to lead the growth of other sectors by eleven (11) percent under the 11th Malaysia Plan (RMK-11) which promises a positive and rapid economic growth in the construction industry [1].

The rapidity and growth of the construction industry cause these construction parties to have sophisticated network communication systems to ensure the smooth delivery of information. One of 
the most popular examples of communication networks today is the Internet. Nowadays, the world is preparing for a new revolution in the industry. The first industrial revolution was a steam-based industry, the second industrial revolution was an electrical-based industry followed by a third industry-based information technology revolution. Now, the world is moving towards a new revolution which is Industrial Revolution 4.0 where Internet of Things is the basis of this new industrial revolution [2].

Internet of Things is a smart network that can detect, control, and program objects automatically [3]. The Internet of Things has come to represent electrical or electronic devices, of varying sizes and capabilities, that are connected to the Internet, but excluding those primarily involved in communications with human beings, i.e., the traditional Internet [14]. The scope of the connections is ever broadening beyond basic machine-to-machine communication [15]. Internet of Things allows its surroundings to be connected and communicate directly and indirectly. Internet of Things generally works by connecting objects to the internet and using the connection to provide remote monitoring or control over the object. Forecasts say there are 75.44 billion devices connected to the Internet of Things by 2025 and people will experience life surrounded by networks that reach a trillion of a lifetime [4]. This is an indication of how far the construction industry is prepared with the growth of this IoT network.

Presently, Internet of things facing major challenges that different networks coexist and the big data size of the IoT [16]. Other current issues, such as address restriction, automatic address setup, security functions such as authentication and encryption be affected in implementing the concept of the internet of things but by ongoing in technological developments in construction industry these challenges will be overcome. The internet of things promises future new technologies when related to cloud computing and big data. By integrating them with the internet of things, application challenges in construction industry will be developed as soon [11].

The construction industry should emphasize the use of this Internet of Things applications as in the future the construction sector will become increasingly complex and complicated. If there is no application that will facilitate the work involved, the construction industry will be left behind by the improvement of other industries.

\section{Literature Review}

\subsection{Industrial Revolution 4.0}

According to Schwab [2], the Industrial Revolution 4.0 is a change driven by three major technological domains, namely physical, digital and biological. This revolution will affect human life in terms of the way they live, work and have relationships. The Industrial Revolution is undergoing changes for almost four times start with Industrial Revolution 1.0 on a steam-based industry, the Industrial Revolution 2.0 on an electrical-based industry, the Industrial Revolution 3.0 on an information technology-based industry and the Industrial Revolution 4.0 on a digital-based industry where the IoT is the basis of this revolution.

Additionally, Schwab [2] stated there are nine major cores in the Industrial Revolution 4.0 which is Internet of Things (IoT), Autonomous Robot, Big Data, Cloud Computing, Augmented Reality (AR), Simulation, Additive Manufacture, Cybersecurity and System Integration. 


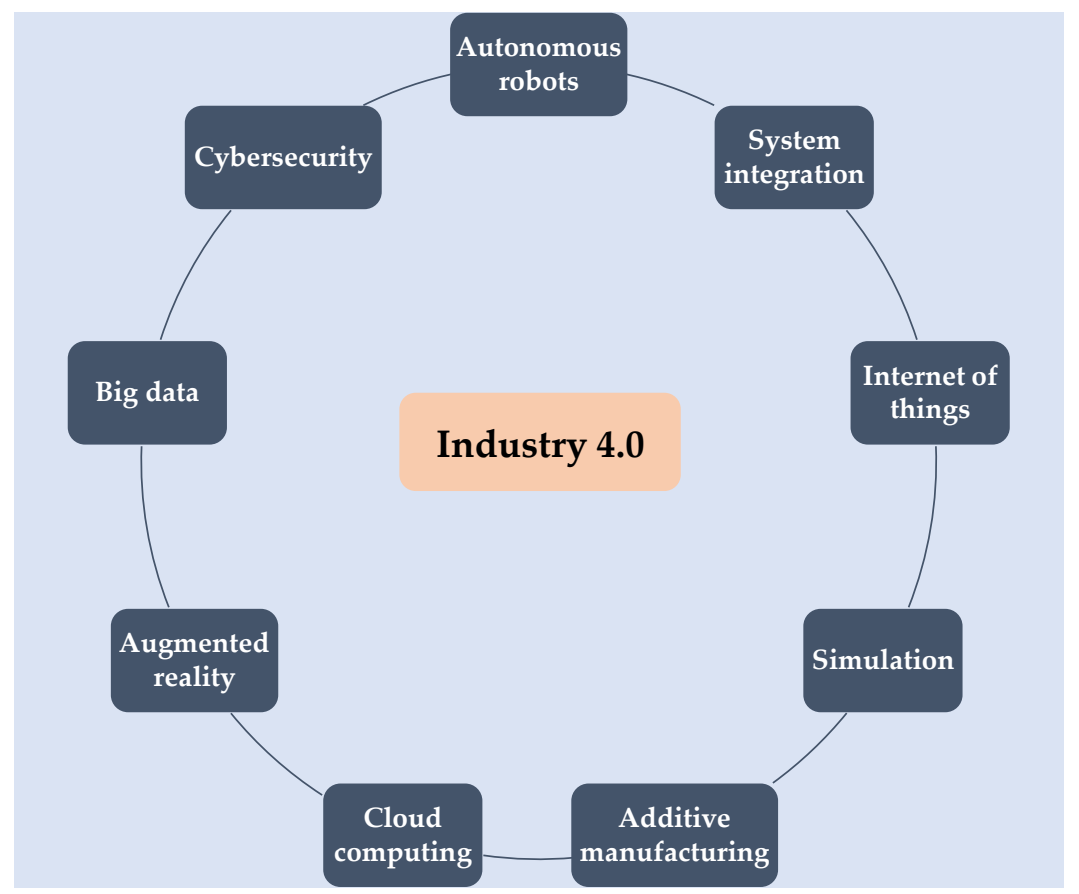

Figure 1. Core of Industrial Revolution 4.0 (Source: The Forth Industrial Revolution)

\subsection{Internet of Things in Construction}

\section{a. Smart Communication}

Social media such as Facebook, Whatsapp, and Telegram are increasingly popular communication tools today. Social media only requires an internet connection to use it as a communicating tool such as exchanging opinions, uploading current status and making video calls. At present, this social media has been upgraded to allow the creation of discussion groups and delivery of documents more easily and quickly. Meanwhile, according to Lavelle [5], e-tendering is also one of the tools of information technology in the construction industry that also uses internet connection. The e-tender concept makes information distributed easier to bidders and the delivery process of the document will be faster and quick because the distance is no longer a problem in the use of this system. In terms of management, ScanMarker is a digital pen capable of scanning any printed text and transmitting the text into any device such as computers, tablets and smartphones via Bluetooth connections. This device is able to save typing time, translating around 40 languages and text scans capable of producing sound [6].

\section{b. Remote Operation}

Construction is exposed to complex environments, so construction requires effective monitoring to ensure the smoothness of the project. According to Burger [7], via the Internet of Things, instruction from far able to be made if machines are physically connected or wirelessly connected to the web. A machine that is easily recognizable as a drone is capable of receiving instructions then able to operate alone in monitoring areas. Dron is used as a tool to monitor employee health and safety as well as to monitor construction progress from time to time [8].

\section{c. Supply Replenishment}

Construction requires an adequate supply of materials to ensure the smoothness of the project. However, the late supply of materials cases often occurs at the site due to time-consuming of the delivery process. Through the Internet of Things approach, when the supply unit is labeled with an Radio Frequency Identification (RFID) tag, the system on the site can automatically count the quantity. When the count falls below a certain level, the system will provide information to the central system to place more orders [7]. In addition, the RFID tags placed on the goods allow them to be 
easily accessible, knowing the suitability of the temperature of the item, handling carefully and informing if the item has damage, expiration and stocks are decreasing [9].

\section{d. Maintenance of Machinery and Equipment}

Equipment maintenance work is important to avoid additional costs due to severe damage. Internet of Things via sensor approach enables it to send information about the current status of equipment or machinery for the need for any maintenance or repair [7]. According to Levy [10], heavy construction machinery is often equipped with sensors where these sensors can monitor from a distance as an indication of the necessary maintenance such as temperature fluctuations, excessive vibrations and so on. In addition, the use of equipment that is too long to end up potentially causing maintenance on the equipment. Through the Interconnected Internet (IoT), construction time can be automatically logged using sensors scanning so that the equipment will work in accordance with timeliness and give warning of the time being used [7].

\section{e. Power, Fuel and Energy Savings}

Unmanaged power and fuel consumption will result in wastage that will impact the cost of the project. Through the Internet of Things approach, the site can send information about the amount of electricity used and the lighting usage after an office hour can be adjusted for energy saving. Additionally, machines and machinery can be controlled to turn them off automatically if they do not move in seconds for fuel-saving purposes [7].

\section{f. Augmented Reality (AR)}

Google Glass has offered AR for a variety of usage. AR combined with the Internet of Things network to transmit information and make it visible on Google Glass. This allows employees to receive noticeable instructions on Google Glass about what to do, danger alerts, current work productivity and more [7].

\section{g. Building Information Modeling (BIM)}

The computer model used to monitor the construction of its lifespan can be practiced by placing sensors in the building that has been built. This sensor can then transmit state information on materials influenced by climate change and time circulation, providing information on possible changes in energy efficiency and structural conditions when there is an earthquake (Burger, 2017). In addition, data from the Internet of Things can also be used as an informant on energy consumption patterns, temperature changes and human movement in buildings [10].

\section{h. Give an Efficient Way}

According to Cunha [11], the selection of inefficient transport routes would result in substantial fuel consumption and delay the delivery process. Through the Internet of Thing, sensors acting as General Packet Radio Service (GPRS) will provide drivers with information on the most efficient and fast travel routes. The Waze app is one of the applications that can provide a short travel option where the main function is as a map to the user.

\section{i. Security Control}

There is a potential for material theft occurs at the site if the placements are not monitored properly. Using RFID tags, any material or theft of items is easily resolved as these sensors will notify the current location of the materials or item [11]. Additionally, the Internet of Things approach is also used to create security devices known as August Smart Lock that operate over Wi-Fi networks. This device is installed on the main door and is able to lock and unlock the door from anywhere using the downloaded application into the smartphone. This device is capable of detecting guest images and triggering an alarm when sensors detect threats [9]. 


\section{j. Managing Workers}

Companies need to ensure that crews and contractors work productively under workplace compliance considerations, union rules, optimum security, and at the best efficiency. Through an Internet of Things approach, sensors connected to the worker badge are able to inform the project manager of the existence of their employees, skills and qualifications for the work and how much time they spend doing certain tasks. Information from the Internet of Things can then provide information to payment systems, human resource managers, finance, and planning [11].

\section{k. Worker Health}

Handling equipment and machinery for too long may cause workers to experience fatigue, which in turn disturbs their work productivity [7]. Through the Internet of Things, a device in the form of a watch has been invented as a tool capable of recording pulse rates, elevation from one place to another and its user location based on Global Positioning System (GPS) [8].

\section{Environmental Monitoring}

A device known as Waspmote Plug \& Sense uses the Internet of Things concept in environmental monitoring. The device is equipped with a remote-control sensor capable of monitoring fire, flood threats and air quality. Sensors will monitor this threat and communicate using Wi-Fi to send information to recipient centres [12].

\section{m. Building Structure Health Monitoring}

Libelium [12] reports that the Internet of Things is used as a building health monitor where the sensor is known as the Linear Displacement Sensor placed on structures capable of detecting vibrations, cracks and conditions of building materials and civil structures such as historic bridges and monuments.

\section{n. Waste Management}

Through an Internet of Things approach, a smart waste management system implementation has been implemented using IR sensors, microcontrollers and Wi-Fi modules [16]. This system guarantees the immediate cleaning of the trash when the trash reaches maximum levels. If the trash cannot be cleaned within a certain time, the record is sent to the authorities and appropriate action taken against the relevant contractor.

\section{Methodology}

The objective of this study is to identify the types of Internet of Things application used in the construction industry in Malaysia. The scope of the study consists of construction industry players namely government agencies comprising JKR and CIDB, developers, architects, engineers, quantity surveyors and class G7 contractors. This is because, based on the literature review, the author believes that the application of Internet of Things in construction will be used by all industry players. The study sample is the states in Malaysia. Author choose a large sample to get a view from each construction parties around the states in Malaysia.

The study uses questionnaire forms as an instrument for obtaining quantitative data. Then the data were analysed using nominal analysis based on the highest mod respondents who answered "Yes" or "No" regarding the type of Internet of Things applications they use in the construction industry. The analysis is then presented in the form of graphs and tables.

\section{Analysis and Result}

\subsection{Type of Internet of Things Application Used in the Construction Industry in Malaysia.}

In order to fulfil this objective, a questionnaire form first evaluates the extent to which the industry players know about the Internet of Things application that has been offered in the market. This assessment is conducted through a nominal analysis using the "Yes" or "No" answer and the 
analysis results are shown in percentage values. Then, after assessing knowledge, a questionnaire will evaluate if industry players use or not use the Internet of Things application. This assessment is also made through a nominal analysis using "Yes" or "No" answers and the results of the analysis are also presented in percentages.

Table 1. Highest ranking and percentage of knowledge on types of Internet of Things applications.

\begin{tabular}{lcc}
\hline Types of Internet of Things Applications & Highest Ranking & Percentage \\
\hline Use of social media and use of email & 1 & 100 \\
Use of website as a referral source to obtains data about & 2 & 95 \\
company profile, act, policy, price quotes and others. & 3 & 93 \\
Use of GPRS (Google Maps or Waze). & & 3 \\
\hline
\end{tabular}

Based on Table 1, the use of social media and email is an application which is well-known by respondents which representing a full percentage of $100 \%$. The use of websites is the second highest known by $95 \%$ respondents. The third application that many of the respondents know is the use of GPRS like Google Maps or Waze by $93 \%$.

Table 2. Lowest ranking and percentage of knowledge on types of Internet of Things applications.

\begin{tabular}{lcc}
\hline Types of Internet of Things Applications & Lowest Ranking & Percentage \\
\hline Use of ScanMarker. & 1 & 33 \\
Use of sensor technology to manage waste. & 2 & 38 \\
Use of SmartWatch. & 3 & 45 \\
Use of Augmented Reality (AR) technology. & & \\
\hline
\end{tabular}

Based on Table 2, the use of ScanMarker is an application which is less known by respondents with a percentage of only $35 \%$. In the meantime, the use of sensor technology to manage waste is a second application that is less known to respondents with a percentage of $38 \%$. Then, the use of SmartWatch and Augmented Reality (AR) was the third lowest application that was also less known by respondents with a percentage of $45 \%$.

Table 3. Highest ranking and percentage of usage on types of Internet of Things applications.

\begin{tabular}{lcc}
\hline Types of Internet of Things Applications & Highest Ranking & Percentage \\
\hline Use of social media and use of email & 1 & 100 \\
Use of website as a referral source to obtains data about & 2 & 93 \\
company profile, act, policy, price quotes and others. & 3 & 92 \\
Use of GPRS (Google Maps or Waze). & 3 \\
\hline
\end{tabular}

Based on Table 3, the use of social media and email is an application that is heavily used by respondents with a maximum percentage of $100 \%$. The use of websites is the second highest application used by $93 \%$ of respondents. The third application that many respondents use is the use of GPRS like Google Maps or Waze by $92 \%$.

Table 4. Lowest ranking and percentage of usage on types of Internet of Things applications.

\begin{tabular}{lcc}
\hline Types of Internet of Things Applications & Lowest Ranking & Percentage \\
\hline Use of SmartWatch. & 1 & 8 \\
Use of sensor technology to manage waste. & 2 & 10 \\
Use of ScanMarker. & 3 & 13 \\
\hline
\end{tabular}

Based on Table 4, the use of SmartWatch is an application which is less used by respondents with a percentage of only $8 \%$. The use of sensor technology to manage garbage is also the second 
application which is less used by respondents with a percentage of $10 \%$. Then, the use of ScanMarker is the lowest third application that is also less used by respondents with a percentage of $13 \%$. Unlike other products, Scanmarker does not use widely to scan the working drawing. Instead, the printed drawing is scanned and captured as a raw image - and processed to a high quality image, ready for recognition by construction personnel.

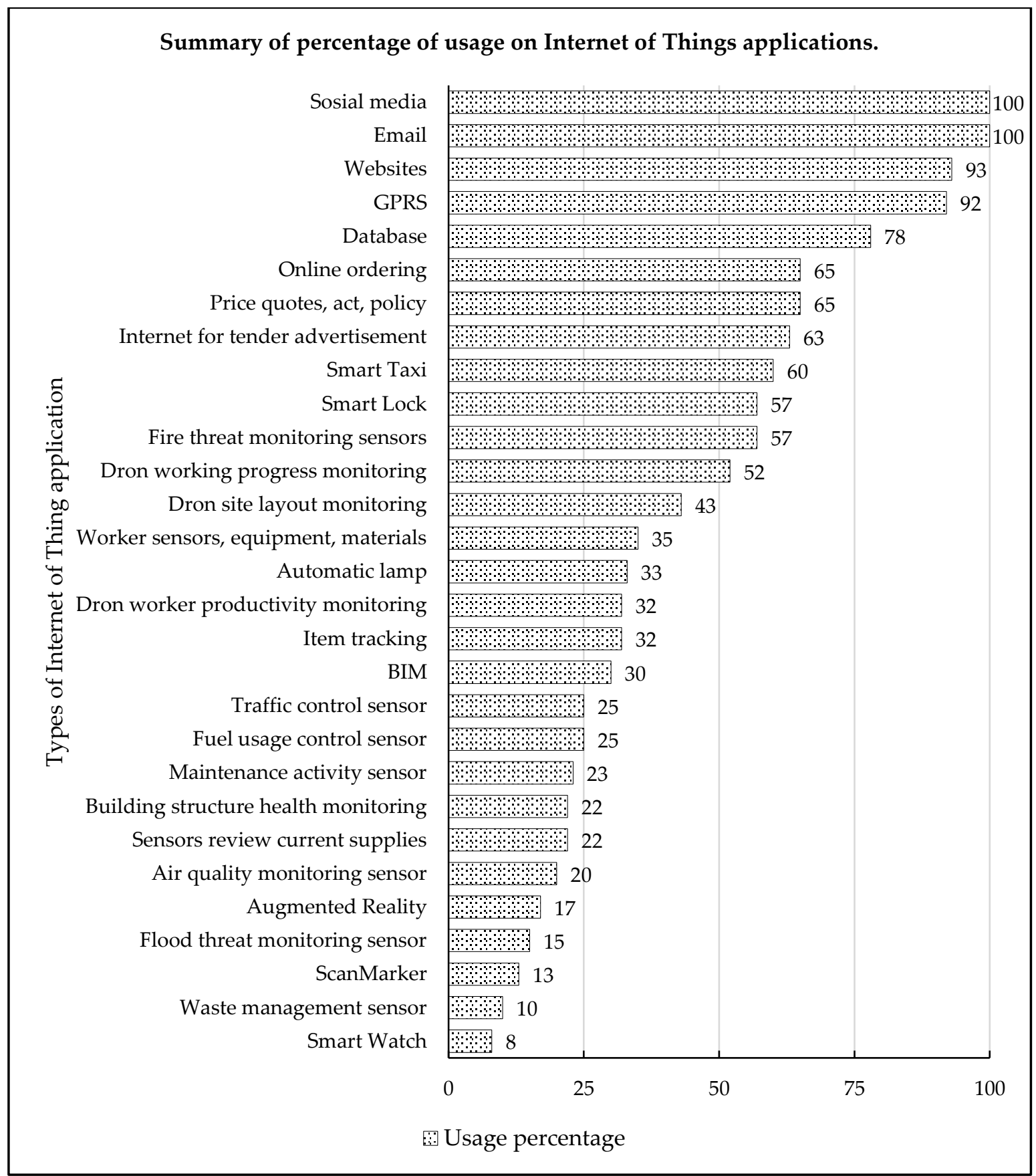

Figure 2. Summary of percentages of usage on Internet of Things application.

Figure 2 shows 29 types of Internet of Things applications that have been carried out. In general, the percentage of respondents using the Internet of Things applications is lower than the percentage of respondents who did not use the app. This is because $41 \%$ of respondents are in the percentage of $50 \%$ to $100 \%$ where this percentage represents the respondents who are more using the applications than those who do not use it. 4 types of Internet of Things applications that get the highest percentage of users are social media and email, website and GPRS usage which represent $100 \%, 93 \%$ and $92 \%$ respectively. A total of 8 applications also have a satisfactory rate of usage where the percentage of usage is within $50 \%$ to $90 \%$. 
3 types of Internet of Things applications that earn the lowest percentage of usage is SmartWatch, sensor technology for managing waste and ScanMarker which account for $8 \%, 10 \%$ and $13 \%$ respectively. Next, up to 14 types of applications are also in the percentage of the lowest usage rate within $15 \%$ to $49 \%$ only.

\section{Conclusion}

Based on the results of this study, there are four (4) types of Internet of Things applications occupy the highest percentage of usage. The use of social media such as Whatsapp, Telegram and Facebook Messenger is a type of Internet of Things application that is heavily used by construction industry players. Then followed by the use of email that serves as an exchange of information between players of this industry. Both applications get the most and the same response where each respondent used it. The second highest application is the use of the website as a reference source for data on company profiles, acts, policies, price quotes and others. The next third-highest application is the use of GPRS like Google Maps or Waze during delivery of goods or documents to provide an efficient route.

There are four (4) types of Internet of Things applications that have the lowest usage percentage compared to other applications. The least-used application is the use of sensor technology to monitor the flood threats on the site. Then followed by the use of sensor technology to manage the waste and the use of Scan-Marker during work that has the same percentage of usage. The third application is the use of SmartWatch to monitor health or location. These four applications have a very poor percentage of usage because the percentage does not exceed $20 \%$ of all respondents.

However, the findings show that the use of Internet of Things applications is still under-utilized in the construction industry in Malaysia. This is because there are only 12 types of applications that are higher in usage rates than those that do not use them, and 17 applications are less used.

The evaluation of the respondents' knowledge of the Internet of Things application found that the majority of respondents had known each type of Internet of Things application. This proves that the construction industry players are aware of the presence of this application although its usage is still less than the knowledge on the application.

Consequently, in order to extend the use of these Internet of Things applications, they should have further implementation and encouragement of each industry player to encourage them on the use of this application in the construction industry. The Internet of Things market in Malaysia is likely to be another factor of the least use of this application in the construction industry. The price of Internet of Things products is also one of the factors causing the lack of usage rate of Internet of Things application because most of the Internet of Things products are expensive and using current technology. This paper surveyed some of the most important applications of IoT with focus on construction industry, however, future research may be conducted on implementation the internet of things concept in building projects and the case study may be conducted to make the concept of IoT feasible.

\section{Acknowledgment}

The authors would like to take the opportunity to thank and express gratitude to the survey respondents of this research.

\section{References}

[1] Ahmed A. A. Hamid (12 April, 2017). Sektor pembinaan dijangka berkembang 8 peratus. Utusan Online. Available: http://www.utusan.com.my/bisnes/ekonomi/sektor-pembinaan-dijangka-berkembang-8-peratus-1.468272

[2] Klaus Schwab (2016). The Forth Industrial Revolution. United Kindom: Portfolio UK.

[3] Kevin Ashton (2009). That "internet of things" thing. RFID Journal, 7(22), 97-114.

[4] In Lee and Kyoochun Lee (2015). The Internet of Things: Applications, investments, and challenges for enterprises. Business Horizons (58), 431-440. 
[5] Derek Lavelle and Andrew Bardon (2009). "E-tendering in construction: time for a change?" Northumbria Working Paper Series: Interdisciplinary Studies in the Built and Virtual Environment 2.2 (2009): 104-112.

[6] Reuven Regev. Scanmarker: The Digital Highlighter. Retrieved 25 November, 2017, from No more retyping - Use Scanmarker to scan notes instantly to your computer, smartphone or tablet! https://scanmarker.com.

[7] Rachel Burger (2017). How "The Internet of Things" is Affecting the Construction Industry. Retrieved 21 October 2017. Available: https://www.thebalance.com/how-internet-affects-the-construction-industry-845320.

[8] Rosdiadee Nordin (2016). Objek Rangkaian Internet (Internet of Things) - Perkembangan Terkini dan Potensi di Malaysia, 26 May, 2016. Retrieved 18 November, 2017. Available: http://www.majalahsains.com/objek-rangkaianinternet-internet-of-things-perkembangan-terkini-dan-potensi-di-malaysia.

[9] James Macaulay and Markus Kückelhaus (2015). Internet of things in logistic. Troisdorf: DHL Customer Solutions \& Innovation.

[10] Jacqi Levy (2017). Internet of Things blog. Retrieved from 4 BIG ways the Internet of Things is impacting design and construction, 12 February, 2017. Available: https://www.ibm.com/blogs/internet-of-things/4-big-ways-the-Internetof-Things-is-impacting-design-and-construction.

[11] Luciano Cunha (2014). Building with the Internet of Things in the Contruction Industry. To Increase, 25 February, 2014. Available: https://www.to-increase.com/internet-of-things-construction.

[12] Libelium (2012). "50 Internet of Things Application". Retrieved 2 October, 2017. Available: http://www.libelium. com/resources/top 50 Internet-of-Things sensor applications rankin.

[13] Navghane, M.S. Killedar, V.M. Rohokale (2016). Internet of Things Based Smart Garbage and Waste Collection Bin. International Journal of Advanced Research in Electronics and Communication Engineering (IJARECE), 5(5), 2016.

[14] Miraz Mahdi, Maaruf Ali, Peter Excell and Richard Picking (2018). Internet of Nano-things, Things and Everything: Future Growth Trends. Future Internet 10, no. 8 (2018): 68, DOI: 10.3390/fi10080068, Available: www.mdpi.com/ 1999-5903/10/8/68/pdf

[15] Benattia, Amina and Maaruf Ali (2008). Convergence of Technologies in the Machine-to-Machine (M2M) Space. In Proceedings of the IEEE International Conference on Applied Electronics, pp. 9-12. 2008.

[16] Zeinab, Kamal Aldein Mohammed and Sayed Ali Ahmed Elmustafa (2017). Internet of Things applications, challenges and related future technologies. World Scientific News 2, no. 67 (2017): 126-148.

(C) 2018 by the author(s). Published by Annals of Emerging Technologies in Computing (AETiC), under the terms and conditions of the Creative Commons Attribution (CC BY) license which can be accessed at http://creativecommons.org/licenses/by/4.0/. 